\title{
Active Choosing or Default Rules? The Policymaker's Dilemma
}

\section{Citation}

Cass R. Sunstein, Active Choosing or Default Rules? The Policymaker's Dilemma (May 15, 2014).

\section{Permanent link}

http://nrs.harvard.edu/urn-3:HUL.InstRepos:12186290

\section{Terms of Use}

This article was downloaded from Harvard University's DASH repository, and is made available under the terms and conditions applicable to Open Access Policy Articles, as set forth at http:// nrs.harvard.edu/urn-3:HUL.InstRepos:dash.current.terms-of-use\#OAP

\section{Share Your Story}

The Harvard community has made this article openly available. Please share how this access benefits you. Submit a story.

Accessibility 


\title{
Preliminary draft 5/14/14 All rights reserved
}

\section{Active Choosing or Default Rules? The Policymaker's Dilemma}

\author{
Cass R. Sunstein"
}

\begin{abstract}
For policymakers, the idea of active choosing has a great deal of appeal, not least because it avoids the charge of paternalism. In many contexts, however, an insistence on active choosing is a form of paternalism, not an alternative to it. The reason is that people might choose not to choose. People are often aware that when the area is complex, difficult, and unfamiliar, active choosing may impose high costs on choosers, who might ultimately err and thus suffer serious harm. In such cases, there is a strong argument for a default rule rather than for active choosing. But if the area is one that choosers understand well, if people's situations are diverse, and if policymakers lack the information that would enable them to devise accurate defaults, then active choosing would be best. A simple framework, based on the costs of decisions and the costs of errors, can provide solutions in a wide range of situations in which policymakers are deciding between active choosing and default rules.
\end{abstract}

\section{A Pervasive Question}

Consider the following problems:

1. Public officials are deciding whether to require people, as a condition for obtaining a driver's license, to make an active choice about whether to become organ donors. The alternatives are to continue with the existing "opt in" system, in which people become organ donors only if they affirmatively indicate their consent, or to change to an "opt out" system, in which consent is presumed.

\footnotetext{
* Robert Walmsley University Professor, Harvard University. This essay draws on longer treatments of related topics, including Cass R. Sunstein, Choosing Not to Choose, Duke LJ (forthcoming 2014), available at http://papers.ssrn.com/sol3/papers.cfm?abstract_id=2377364
} 
2. A public university is deciding among three options: to enroll people automatically in a health insurance plan; to make them opt in if they like; or to say that as a condition for starting work, they must indicate whether they want health insurance, and if so, which plan they want.

3. A utility company is deciding whether to adopt for consumers a "green default," with a somewhat more expensive but environmentally preferable energy source, or instead a "gray default," with a somewhat less expensive but environmentally less desirable energy source, or alternatively to ask consumers which energy source they prefer. Its decision will be subject to regulatory oversight.

4. A social network site is deciding whether to adopt a system of default settings for privacy, or whether to require first-time users to say, as a condition for access to the site, what privacy settings they would prefer. Public officials are interested in the site's decision and are considering a regulatory intervention if the decision does not serve the interests of the site's users.

In these cases, and countless others, policymakers are deciding whether to use or to promote some kind of default rule, or instead to require or to promote some kind of active choice. A great deal of research has shown that for identifiable reasons, default rules have significant effects on outcomes, because they tend to "stick." $F$ For those who reject paternalism and who prize freedom of choice, active choosing has evident appeal. Indeed it might seem far preferable to any kind of default rule.

My goal here is to defend two claims. The first is that in many contexts, an insistence on active choosing is a form of paternalism, not an alternative to it. The reason is that people often choose not to choose, and for excellent reasons.

The second claim is that when policymakers decide between active choosing and a default rule, they should focus on two factors. The first is the costs of decisions: If active choosing is required, are people forced to incur large costs or instead small ones? The second is the costs of errors: Would the number and magnitude of mistakes - from the standpoint of informed choosers themselves - be higher, or lower, with active choosing than with default rules?

These questions lead to some simple rules of thumb. When the area is complex, technical, and unfamiliar, active choosing may impose high costs on choosers, and they might ultimately err. In such cases, there is a strong argument for a default rule rather than for active choosing. But if the area is one that choosers understand well, if the

\footnotetext{
${ }^{1}$ Much of the foundational work has been done by Eric Johnson. For an illuminating overview, see Eric J. Johnson \& Daniel G. Goldstein, Decisions by Default, in The Behavioral Foundations of Policy 417, 41718 (Eldar Shafir ed., 2013).
} 
situations of choosers are diverse, and if policymakers lack the information that would enable them to devise accurate defaults, then active choosing would be best. This framework can help orient a wide range of policy questions, though a great deal of empirical work would be desirable to understand how it applies in different contexts. In the future, it will be especially important for private and public institutions to consider the feasibility of personalized default rules, tailored to particular groups or people, and to explore whether personalization can avoid the problems associated with both active choosing and "mass" defaults.

\section{Active Choosing Can Be Paternalistic}

With the help of modern technologies, policymakers are in an unprecedented position to ask people this question: What do you choose? Whether the issue involves organ donation, health insurance, retirement plans, energy, privacy, or nearly anything else, it is simple to pose that question (and in fact to do so repeatedly and in real time, thus allowing people to signal new tastes and values). Those who reject paternalism, and want to allow people to do their own way, tend to favor active choosing. Indeed, there is empirical evidence that in some contexts, ordinary people will pay a premium to have the authority to choose on their own. ${ }^{2}$ But in other cases, people will plainly pay a premium to be relieved of that very obligation.

Sometimes people explicitly choose not to choose. Sometimes it is reasonable to infer that in particular contexts, their preference would be not to choose. They might fear that they will err. They might not enjoy choosing. They might be busy and lack "bandwidth." They might not want to take responsibility for potentially bad outcomes for themselves (and at least indirectly for others). ${ }^{4}$ They might find the underlying questions confusing, difficult, painful, and troublesome -- empirically, morally, or otherwise. They might anticipate their own regret and seek to avoid it. They might be keenly aware of their own lack of information or perhaps even of their own behavioral

${ }^{2}$ Ernst Fehr et al., The Lure of Authority: Motivation and Incentive Effects of Power, 103 AM. ECON. REV. 1325 (2013). Compare the related phenomenon of "reactance," which suggests a negative reaction to persuasive efforts, produced in part by the desire to assert autonomy. See Louisa Pavey \& Paul Sparks, Reactance, Autonomy and Paths to Persuasion: Examining Perceptions of Threats to Freedom and Informational Value, 33 MOTIVATION \& EMOTION 277 (2009).

${ }^{3}$ On the importance of that concept, see Sendhil Mullainathan and Eldar Shafir, Scarcity: Why Having Too Little Means So Much (2013).

${ }^{4}$ For a demonstration, see Bjorn Bartling \& Urs Fischbacher, Shifting the Blame: On Delegation and Responsibility, 79 REV. ECON. STUD. 67 (2012). On people's preference for flipping a coin, as a way of avoiding responsibility, see Nadja Dwengler et al., Flipping A Coin: Theory and Evidence (2013) (unpublished manuscript, http://www.wiwi.hu-berlin.de/professuren/vwl/mt-anwendungen/team/flipping-acoin). Consider this suggestion, $i d$. at 1: The "cognitive or emotional cost of deciding may outweigh the benefits that arise from making the optimal choice. For example, the decision-maker may prefer not to make a choice without having sufficient time and energy to think it through. Or, she may not feel entitled to make it. Or, she may anticipate a possible disappointment about her choice that can arise after a subsequent resolution of uncertainty. Waiving some or all of the decision right may seem desirable in such circumstances even though it typically increases the chance of a suboptimal outcome." 
biases (such as unrealistic optimism or "present bias," understood as an undue focus on the short-term). In the area of retirement savings or health insurance, informed employees might welcome a default, at least if those who choose who can be trusted.

It is true that default rules tend to stick. Because people suffer from inertia (and thus seek to reduce "effort costs"), because default rules contain information about what outcomes are best or most sensible, and because people do not suffer losses (which default rules help to define), an opt-in design will produce far less participation than an opt-out design. ${ }^{5}$ It is well-established that social outcomes might be decisively influenced by the choice of default, in areas that include organ donation, retirement savings, environmental protection, and privacy. Especially if they are averse to any kind of paternalism, policymakers might want to avoid the influence of default rules and to require active choosing instead. ${ }^{6}$

But active choosing does not avoid paternalism. Whenever policymakers promote active choosing on the ground that it is good for people to choose, they are acting paternalistically. To be sure, nanny states forbid choosing, but they also forbid the choice not to choose. Choice-requiring paternalism might be an attractive form of paternalism, but it is no oxymoron, and it is paternalistic nonetheless.

Suppose, for example, that Jones believes that he is not likely to make a good choice about his retirement plan, and that he would therefore prefer a default rule, chosen by someone who is a specialist in the subject at hand. Or suppose that Smith is exceedingly busy, and wants to focus on her most important or immediate concerns, not on a question about the right health insurance plan for her, or even about the right privacy setting on her computer. Many people believe in freedom of choice on social welfare grounds; they believe that people are uniquely situated to know what is best for them. If so, then that very argument should support respect for people when they freely choose not to choose. Many people believe in freedom of choice on the ground that it is important to respect people's autonomy. If so, then it is also important to respect people's decisions about whether and when to choose. That view seems especially reasonable in view of the fact that people are in a position to make countless decisions, and they might well decide that they would like to exercise their autonomy by focusing on their foremost concerns, not on what seems trivial, boring, or difficult.

If people are required to choose even when they would prefer not to do so, active choosing counts as a species of nonlibertarian paternalism in the sense that people's own choice is being rejected. When people prefer not to choose, required choosing is a form of coercion. If, by contrast, people are asked whether they want to choose, and can opt out of active choosing (in favor of, say, a default rule), active choosing counts as a form of libertarian paternalism. In some cases, it is an especially attractive form. A private or public institution might ask people whether they want to choose the privacy

\footnotetext{
${ }^{5}$ See Johnson and Goldstein, supra note.

${ }^{6}$ See Riccardo Rebonato, Taking Liberties: A Critique of Libertarian Paternalism (2012).
} 
settings on their computer, or instead rely on the default, or whether they want to choose their electricity supplier, or instead rely on the default.

With such an approach, people are being asked to make an active choice between the default and their own preference, and in that sense, their liberty is fully preserved. Call this simplified active choosing. Simplified active choosing has the advantage of avoiding the kinds of pressure that come from a default rule, while also allowing people to rely on such a rule if they like. This approach has evident appeal, and in the future, it is likely to prove attractive to a large number of institutions, both public and private.

To be sure, we could imagine hard cases in which a choice not to choose seems to be an alienation of freedom. In the extreme case, people might choose to be slaves or otherwise to relinquish their liberty in some fundamental way (consider marital choice, or freedom of speech or religion). It is a complex question which cases fall in this category. But even if the category is not small, it cannot easily to taken as a general objection to the proposition that on grounds of welfare and autonomy, people should be allowed not to choose.

It is important to acknowledge that the choice not to choose may not be in the chooser's interest (as the chooser would define it). Perhaps the chooser chooses not to choose only because he lacks important information (which would reveal that the default rule might be harmful) or suffers from some form of bounded rationality. Perhaps the chooser is myopic and is excessively influenced by the short-term costs of choosing, which might require some learning (and hence some investment), while underestimating the long-term benefits, which might be very large. A form of "present bias" might infect the decision not to choose.

But for those who reject paternalism, these kinds of concerns are usually a justification for providing more and better information or for some kind of nudge - not for blocking people's choices, including their choices not to choose. In light of people's tendency to overconfidence, the choice not to choose might even be peculiarly likely to be right, which would create serious problems for choice-requiring paternalism. Consider in this regard behavioral evidence that people spend too much time trying to make precisely the right choice, in a way that leads to significant welfare losses. In many situations, people underestimate the temporal costs of choosing and exaggerate the benefits, producing "systematic mistakes in predicting the effect of having more, vs. less, choice freedom on task performance and task-induced affect.",

If people prefer not to choose, they might favor either an opt-in or opt-out design. In the context of both retirement plans and health insurance, for example, many people prefer opt-out, on the ground that automatic enrollment overcomes inertia and procrastination, and produces sensible outcomes for most employees. Indeed, the Affordable Care Act requires automatic enrollment by large employers, starting in

\footnotetext{
${ }^{7}$ See Botti \& Hsee, supra note, at 161.
} 
2015. For benefits programs that are either required by law or generally in people's interests, automatic enrollment has considerable appeal.

In the context of organ donation, by contrast, many people prefer an opt-in design. In that context, of course, there is a strong argument for active choosing, on the ground that as compared to opt-in, it would save lives, and could also avoid some of the moral objections that might be mounted against opt-out. But as the experience in several states suggests, some people object to active choosing, and favor opt-in, on the ground that they do not want to be forced to make the choice. In view of the life-saving potential of active choosing, that objection may not be convincing, but it is at least intelligible.

Are people genuinely bothered by the existence of default rules, or would they be bothered if they were made aware that such rules had been chosen for them? We do not have a full answer to this question; the setting, and the level of trust, undoubtedly matter. But note in this regard the empirical finding, in the context of end-of-life care, that even when they are explicitly informed that a default rule is in place, and that it has been chosen because it affects people's decisions, there is essentially no effect on what people do - a finding that suggests that people are not uncomfortable with defaults, even when they are made aware that choice architects have selected them, and do so because of their significant effect. ${ }^{8}$ More research would be highly desirable on this question.

\section{Decision Costs and Error Costs}

The choice between active choosing and default rules cannot be made in the abstract. To know which is best, policymakers need to investigate two factors: the costs of decisions and the costs of errors. In some cases, active choosing imposes high costs, because it is time-consuming and difficult to choose. In other cases, the decision is relatively easy and the associated costs are low. Sometimes people actually enjoy making decisions, in which case decision costs turn out to be benefits. In some cases, active choosing reduces the number and magnitude of errors, because choosers have far better information, about what would promote their welfare, than policymakers do. In other cases, active choosing increases the number and magnitude of errors, because choosers lack such information, and policymakers have a great deal of it.

With these points in mind, two propositions are clear, and they can help orient the inquiry in diverse settings. First, policymakers should prefer default rules to active choosing when the context is confusing and unfamiliar, when people would prefer not to choose, and when the population is not heterogeneous along any relevant dimension. The last point is especially important. Suppose that with respect to some benefit, one size fits all or most, in the sense that it promotes the welfare of a large percentage of the affected population. If so, active choosing might be unhelpful or unnecessary.

\footnotetext{
${ }^{8}$ See George Loewenstein et al., Warning: You Are About To Be Nudged (2014) (unpublished manuscript).
} 
Second, policymakers should generally prefer active choosing to default rules when choice architects lack relevant information, when the context is familiar, when people would actually prefer to choose (and hence choosing is a benefit rather than a cost), when learning matters, and when there is relevant heterogeneity. Suppose, for example, that with respect to health insurance, people's situations are highly diverse, so that any default rule will be ill-suited to most or many. If so, there is a strong argument for active choosing.

To be sure, the development of personalized default rules, designed to fit individual circumstances, might solve or reduce the problems posed by heterogeneity. ${ }^{9}$ As data accumulates about what informed people choose, or even about what particular individuals choose, it will become more feasible to devise default rules that fit diverse situations. With retirement plans, for example, demographic information is now used to produce different initial allocations, and travel websites are able to incorporate information about past choices to select personalized defaults (and also advice). For policymakers, the rise of personalization promises to reduce the costs of "mass" defaults and to reduce the need for active choosing, though personalization can raise serious questions about both feasibility and privacy.

There is a final point, which is that active choosing has the advantage of promoting learning and thus the development of preferences and values. In some cases, policymakers might know that a certain outcome is in the interest of most people, but they might also believe that it is independently important for people to learn about the underlying questions, so that they can use the "stock" of what they learn to make choices in multiple areas in the future. In the context of decisions that involve health and retirement, it may be valuable for people to develop the kinds of understandings that will enable them to choose well for themselves. Those who favor active choosing tend to emphasize this point and to see it as a powerful objection to the use of default rules. They might be right, but the context greatly matters. People's time and attention are limited, and the question is whether it makes a great deal of sense to force them to develop a capital stock in one area when they would prefer to focus on others.

\section{Conclusion}

In many contexts, the apparent opposition between active choosing and paternalism is illusory, even a logical error. The reason is that some people choose not to choose, or would do so if they were asked. Nanny states forbid people from choosing, but they also forbid people from choosing not to choose. If policymakers are overriding that particular choice, they may well be acting paternalistically.

We have also seen that the argument for active choosing, or instead for some kind of default rule, depends largely on the costs of decisions and the costs of errors. Where people are relevantly heterogeneous, and where choice architects lack information or

\footnotetext{
${ }^{9}$ See Cass R. Sunstein, Deciding By Default, 162 U Pa L Rev 1 (2013).
} 
neutrality, active choosing has real advantages. But if the area is highly technical and if a default rule is accurate, a requirement of active choosing is unlikely to make a great deal of sense. When choice architects overlook this point and nonetheless insist on active choosing, they might well be behaving paternalistically, and in a way that reduces both the welfare and the autonomy of those whom they are seeking to help. In such cases, choice-requiring paternalism should be avoided. 